REVIEW

\title{
Assessment of obstructive sleep apnoea (OSA) in children: an update
}

\author{
Valutazione critica del bambino con apnea ostruttiva notturna \\ S. SAVINI ${ }^{1}$, A. CIORBA ${ }^{1}$, C. BIANCHINI ${ }^{1}$, F. STOMEO ${ }^{1}$, V. CORAZZI ${ }^{1}$, C. VICINI $^{2}$, S. PELUCCHI ${ }^{1}$ \\ ${ }^{1}$ ENT Department, University Hospital of Ferrara, Italy; ${ }^{2}$ Head-Neck and Oral Surgery Unit, Morgagni Pierantoni \\ Hospital, Azienda USL della Romagna, Forlì, Italy
}

\section{SUMMARY}

OSA is a condition characterised by episodes of complete or partial obstruction of the upper airway, associated with blood-gas changes and atypical sleep patterns. Early diagnosis of OSA may reduce the occurrence of systemic complications over time, although the diagnosis of OSA is, unfortunately, often late. The aim of the work is to review the current concepts in evaluation of paediatric obstructive sleep apnoea (OSA), with an updated revision of the literature considering risk factors, clinical manifestations, and basic and advanced assessment in the paediatric population. For this narrative review, PubMed, Embase and Cinahl databases were searched for the last 10 years, according to PRISMA criteria/guidelines. Assessment of paediatric OSA remains challenging and paediatric patients should always be carefully evaluated; polysomnography is the gold standard for diagnosis of paediatric OSA.

KEY WORDS: Obstructive sleep apnoea $\bullet$ OSA • Children $\bullet$ Management $\bullet$ Polysomnography

\section{RIASSUNTO}

Questo lavoro vuole proporre un'attenta ed aggiornata revisione della letteratura in merito alla valutazione critica delle apnee ostruttive notturne (OSA) nel bambino, in particolare valutando i fattori di rischio implicati, le manifestazioni cliniche e l'iter diagnostico clinicostrumentale. Le apnee ostruttive notturne nel bambino si caratterizzano per la presenza di episodi di completa o parziale ostruzione delle vie aeree superiori associate a modificazioni dell'emogas-analisi e ad un riposo notturno anomalo. La corretta e precoce diagnosi di questa condizione, sebbene ancora oggi spesso sia posta in ritardo, può ridurre l'insorgenza di complicanze sistemiche. È stata eseguita una revisione della letteratura, attraverso una ricerca di articoli scientifici presenti nei database PubMed, Embase e Cinahl negli ultimi 10 anni, in base ai criteri / linee guida PRISMA. La valutazione dell'OSA pediatrica è complessa e i pazienti pediatrici dovrebbero essere sempre gestiti con molta attenzione; la polisonnografia è attualmente la tecnica "gold standard" per la diagnosi dell'OSA pediatrica.

PAROLE CHIAVE: Apnea ostruttiva notturna $\bullet$ OSA $\bullet$ Bambini $\bullet$ Management $\bullet$ Polisonnografia

\section{Introduction}

Obstructive sleep apnoea (OSA) is a condition characterised by episodes of complete or partial obstruction of the upper airway, associated with blood-gas changes and atypical sleep patterns; when present in children and if inadequately diagnosed/treated, it can be associated with behavioural problems, learning difficulties, cardiovascular complications and growth retardation ${ }^{1-3}$. Early diagnosis of the condition may reduce the occurrence of systemic complications over time, although the diagnosis of OSA is, unfortunately, often late ${ }^{4}$.

During sleep, in the child, there is a moderate physiological increase in the upper airways resistance ${ }^{5}$. Children snore more rarely than adults, and any obstructive apnoeic episode must be considered pathological ${ }^{6}$.

Sleep breathing disorders (SBD) include, in increasing order of severity: (i) simple snoring, (ii) syndrome of increased respiratory resistance (Upper Airways Resistance Syndrome - UARS), (iii) obstructive hypoventilation, and (iv) OSA. OSA is the most severe sleep respiratory disorder. Simple snoring (i) is characterised by vibratory noises of the soft palate during the inspiratory phase: it is described as an expression of partial obstruction of the upper digestive airway and is often associated with OSA or UARS. Until 6 years, simple snoring is present in $10 \%$ of children, under 10 years in $27 \%$ and in $47 \%$ during upper airway inflammation. Main causes of simple snoring are adeno-tonsillar hypertrophy, obesity, nasal respiratory obstructions and upper respiratory tract infections. Apart from snoring, forced oral breathing, mouth and dry lips, difficulty swallowing, halitosis and dyslalia can be present during the day. 
UARS (ii) was first described in 1992 by Guilleminault ${ }^{7}$, who observed that some children showed an increase respiratory muscle effort during sleep due to excessive resistance of the upper airway and increased negative endo-oesophageal pressure. The respiratory efforts are associated with arousal and fragmentation of sleep. Reported clinical consequences are poor weight development, reduced scholastic performance, daytime irritability and poor development in height due to reduction of growth hormone (GH) secretion, which occurs during sleep. The diagnosis of UARS can be suspected clinically, and confirmed by polysomnography (PSG).

Obstructive hypoventilation (iii) is defined as prolonged hypoventilation associated with hypoxia and hypercapnia, without complete cyclic airway obstruction ${ }^{5}$. In the child, there is a different pattern of recruitment of dilator muscles, characterised by greater muscular activation that is able to prevent complete collapse of the airways ${ }^{8}$. Another great difference between prolonged hypoventilations and true obstructive apnoea is the reduced disorder of sleep structure; in the child affected by obstructive hypoventilation, awakenings occur more rarely.

OSA (iv) in the paediatric population is characterised by a prolonged and partial obstruction of the upper airway, typical of obstructive hypoventilation, interrupted by total obstruction with hypoxaemia. In the paediatric population, any respiratory pause is considered apnoea, regardless of the duration (OSA = apnoea $/$ hypopnea index (AHI) equal or more than 1).

Correct diagnosis of SBD is often complex, also due to the lack of differential diagnostic instrumental criteria among the various entities of infantile SBD. The incomplete instrumental codification associated with the poor correlation between severity of paediatric OSA and daytime symptomatology often leads to underestimation and late diagnosis of SBD in children.

The aim of this paper is to review the current concepts in evaluation of paediatric OSA, offering an updated revision of the literature data considering risk factors, clinical manifestations, and basic and advanced assessment in the paediatric population.

\section{Methods}

The PubMed, Embase and Cinahl databases were searched for the last 10 years (from January 2008 up to December 2017). Full-text articles were obtained in cases where the title, abstract, or key words suggested that the study may be eligible for this review. The medical subject heading (MeSH) terms included: paediatric obstructive sleep apnoea; upper airways resistance syndrome in children; ob- structive hypoventilation in children, polysomnography, sleep apnoea, sleep-disordered breathing, sleep-related breathing disorders.

The search was conducted according to PRISMA criteria/guidelines (http://www.prisma-statement.org/): it was carried out independently and restricted to papers in English (Table I). Initially the total number of papers identified was 125 ; other papers $(n=34)$ were also identified from references in the published literature when all authors agreed about the reliability and importance of these manuscripts, for a total of 159 papers. Inclusion criteria were clinical series and review papers. Exclusion criteria were non-availability of full text; manuscripts not in the English language; case reports.

Therefore, the authors critically evaluated the 159 papers selected, by reading abstracts and/or texts, to decide whether the identified papers were relevant to this search or not. In this case, inclusion criteria were for clinical series, papers with an adequate group of patients studied ( $\mathrm{n}>20$ ); for reviews, papers published on relevant journals and papers showing a rigorous methods and rigorous reporting. Finally, 48 papers resulted appropriate for this review according to all authors.

\section{OSA risk factors in children}

Snoring is reported to occur in 3-15\% of paediatric population, especially between 3 and 6 years (13-35\%). OSA has a reported frequency of $1-5 \%$ of the paediatric population, with a peak incidence between 2 and 6 years of age (2.5 years in males and 4 years in females), without a significant prevalence of $\operatorname{sex}^{9-11}$. In Italy, Brunetti et al. reported a prevalence of $4.9 \%$ for habitual snoring and $1.8 \%$ for OSA over 1200 children ${ }^{12}$.

The main risk factors reported for OSA are:

- Adenotonsillar hypertrophy. It is the most frequent

Table I. Literature evaluation and selection, according to PRISMA criteria (http://www.prisma-statement.org/).

Total number of articles obtained by PubMed, Embase and 125 Cinahl search

Other papers from references in the published literature 34

Total number of papers identified 159

Paper excluded ${ }^{1} \quad 56$

Article assessed for eligibility 103

Paper excluded $^{2} \quad 36$

Total number of papers finally identified 67

${ }^{1}$ Inclusion criteria were: clinical series, review papers. Exclusion criteria were: nonavailability of full text; manuscripts not in the English language; case reports.

2 Inclusion criteria were: for clinical series, papers with an adequate group of patients studied ( $n>20)$; for reviews, papers published on relevant journals and papers showing a rigorous method and rigorous reporting. 
condition associated with paediatric OSA. There is a significant correlation between tonsillar volume and SBD severity ${ }^{13}$. The classification of tonsil volume, according to the Brodsky scale, is based on the percentage of the oropharynx volume occupied by tonsils. Nevertheless, not all children with "kissing-tonsils" are affected, and the concept of 'airway collapsibility' has been proposed. Airway collapsibility can be evaluated by the critical closing pressure (Pcrit). Marcus et al. ${ }^{14}$, demonstrated an increase in Pcrit in children with OSA compared to those with simple snoring; in other words, children with OSA have the most collapsible upper airway. On the other hand, isolated adenoid hypertrophy is not sufficient to determine OSA, even if may worsen SBD severity in children at risk. The impact of adenotonsillar hypertrophy in the genesis of OSA can be assessed by the success rate of adenotonsillectomy in OSA therapy (83\% in children) ${ }^{15}$.

- Obesity is an important risk factor for paediatric OSA and plays a predominant role in adolescence. In a prospective study, the prevalence of OSA was $4 \%$ in adolescents (aged between 16 and 19), most of which did not show SBD or snoring in their childhood ${ }^{16}$. Obesity and male sex are reported to be the greatest risks for OSA in adolescents. Another study ${ }^{17}$ on 37 obese adolescents showed a $45 \%$ incidence of OSA. It has also been reported that obesity is an independent risk factor for OSA ${ }^{18}$, as less than $50 \%$ of obese children undergoing adenotonsillectomy have complete resolution of their respiratory disorder during sleep ${ }^{19} 20$.

- Inflammation. Recent studies have shown a correlation between OSA and inflammation ${ }^{21}$. Obesity is a condition that even in adolescents can lead to insulin resistance and hepatic steatosis ${ }^{22}{ }^{23}$, and therefore to increased production of different pro-inflammatory mediators such as leptin, interleukin 6 (IL-6) and tumour necrosis factor alpha (TNF- $\alpha)^{24}$. Among children with asthma, those with obesity have a 4-fold increased risk of developing OSA, especially if they have poor pharmacological control. Improvement of OSA in patients treated with montelukast and nasal steroids has been reported ${ }^{25}$.

- Craniofacial anomalies. These include dentofacial anomalies (i.e. ogival palate) and major cranio-facial malformations (i.e. maxillary hypoplasia, retro-micrognathia and macroglossia). Abnormal dentofacial lesions are frequently present in children with OSA $(15-47 \%)$ and improvement of sleep disorders after orthodontic treatment has been reported ${ }^{26}$. However, there are studies showing improvement of the dental situation following adenotonsillectomy, suggesting the hypothesis that dento-facial anomalies may be a consequence of OSA, more than its cause ${ }^{27}$. Children with major cranio-facial malformations have frequent multilevel airway obstruction that must be carefully evaluated by fibroscopy and drug-induced sleep endoscopy (DISE).

- Neuromuscular disorders are characterised by insufficient central and peripheral airflow control with an increased collapsing trend of the pharyngeal-hypopharyngeal walls, reducing its muscle tone ${ }^{28}$. An example in which concomitant anatomical malformations and neuro-muscular disorders coexist is Down's syndrome, characterised by hypoplasia of the upper jaw, ogival palate, macroglossia and muscular hypotonia. OSA is frequently associated with Down's syndrome (81\%); in fact, the American Academy of Pediatrics (AAP) recommends performing PSG in all children with trisomy 21 within four years of age ${ }^{29} 30$.

- Other reported risk factors are a history of prematurity or multiple pregnancies ${ }^{31}$, environmental exposure to smoking, asthma and allergic rhinitis ${ }^{32}$.

\section{Assessment of the paediatric OSA patient}

Clinical evaluation of paediatric OSA patient consists in careful evaluation of history, clinical examination and eventually endoscopic and instrumental assessment. History and clinical examination have been reported to have positive predictive value for diagnosis of OSA of $65 \%$ and $46 \%$, respectively ${ }^{33}$. Nonetheless, clinical evaluation is useful for selecting patients for instrumental tests, such as PSG.

Main reported OSA nocturnal symptoms are habitual snoring, forced oral breathing, abnormal thoracic-abdominal movements, presence of restless sleep with respiratory pauses, frequent awakenings and changes of position, dry mouth, enuresis and profuse sweating. Diurnal symptoms are difficult nasal breathing, hyperactivity and irritability, poor school/academic performance or, more rarely, sleepiness (in adolescent or obese children).

- History. There are few questionnaires available to address OSA symptoms that are suitable for the paediatric population. The Paediatric Sleep Questionnaire proposed by Chervin ${ }^{34}$ is often used in the literature, especially in its short version composed of 22 questions, which has been validated in several languages. It has been shown that $33 \%$ of affirmative answers correlate with a high risk of paediatric SBD. Another questionnaire was proposed by Brouilette et al. ${ }^{35}$; it is a useful screening tool, even if not very reliable compared with polysomnographic results ${ }^{36}$. Recently, the 
I'M SLEEPY questionnaire has been reported to be a valid screening instrument ${ }^{37}$, as well as the paediatric version of the Epworth Sleepiness Scale (ESS) ${ }^{38}$.

- Clinical evaluation. ENT (Ear Nose and Throat) objective examination should rule out the presence of possible tonsillar hypertrophy, which can be classified according to the Brodsky scale, evaluating the percentage of oropharynx occupied by tonsils (considered as the distance between the two anterior pillars). Another classification is based on the evaluation of tonsil size (ranging from 0 to 4: 0 indicates tonsils removed surgically, 1 intravelic tonsils, 2 extravelic tonsils, 3 extravelic tonsils not reaching the midline and 4 tonsils reaching the midline). Another frequently used classification has been reported by Friedman (Mallampati modified); it assesses the position of the tongue within the oral cavity, measuring how it obstructs the airway (grade 1: both uvula and tonsils are entirely visible, grade 2: uvula is visible but not the tonsils, grade 3: soft palate is visible but not the uvula, grade 4: only hard palate is visible) ${ }^{39}$. It is also useful to observe the skeletal class (retrognathic, orthognathic or prognathic), the presence of ogival palate and the facies. BMI and weight growth curve should be carefully assessed. Finally, it is also essential to measure arterial pressure and rule out eventual signs of pulmonary hypertension.

- Endoscopic assessment. Endoscopy with flexible optic fibres allows evaluating patency of nasal cavities (i.e. hypertrophy of the inferior turbinates, presence of septal deviations or choanal atresia, adenoid hypertrophy), tongue base tropism or the possible presence of laryngomalacia. In selected patients, DISE can be indicated. In children, DISE assesses the residual OSA after adenotonsillectomy ${ }^{40}{ }^{41}$. DISE methodology is similar to that of adults, evaluating the site, entity and pattern of obstruction with particular attention to the nose, nasopharynx, oropharynx, tongue base, epiglottis and larynx. Children with multi-level obstructions show more severe OSA ${ }^{42}{ }^{43}$, as in adults. In a study on 82 children with moderate to severe OSA, lateral and/ or multilevel oropharyngeal collapse was reported in most cases ${ }^{44}$. However, the role of DISE in the paediatric population is still controversial ${ }^{45}$.

- Polysomnography (PSG). Presently, PSG represents the gold standard to diagnose OSA in children. The aim of PSG is to: (i) diagnose, differentiate and quantify obstructive apnoeas, mixed apnoeas, central apnoeas; (ii) identify and classify hypopneas and high-resistance syndromes; (iii) evaluate sleep fragmentation. PSG is an expensive exam; it requires specialised equipment and personnel, is time-consuming and often has long waiting lists. PSG can only be performed in a few centres, such as a sleep laboratory in a hospital setting, which allows continuous monitoring ${ }^{46}$. PSG should cover at least two complete nocturnal sleep cycles, without premedication or sleep deprivation, preferably at a distance from any steroid treatment. PSG recordings in children can be longer than adults, due to their sleep times: 11 to 12 hours for small and pre-school children, 9 to 10 hours for school-age children. It is useful to extend the study time in the mornings to record REM sleep (when apnoea is usually worse) ${ }^{47}$. Apnoea is defined as the reduction of airflow of more than $90 \%$ for at least two respiratory cycles; it is considered obstructive if during the whole period the inspiratory effort is continued or increased, it is central if the inspiratory effort is absent, and is mixed if there is a respiratory effort present only during part of the event, especially at the end. Hypopnea is defined as reduction of airflow $\geq 30 \%$ for at least two respiratory cycles; reduction of the air flow is associated with an arousal or a desaturation $>3 \%$. In children, the detection of a single apnoea episode or hypopneas per hour is considered pathological. Three degrees of OSA severity are identified according to the AHI: mild AHI 1-4, moderate AHI 5-9, severe AHI $\geq 10$. The present polysomnographic classification also allows to identify children: 1) at risk of sequelae; 2) at risk of postoperative complications, which require strict clinical and instrumental follow-up; 3) at high risk of OSA even after adenotonsillectomy, requiring further investigations and treatments.

- Nocturnal pulse oximetry. Nocturnal pulse oximetry is a valid initial diagnostic test for SBD and OSA for different reasons: its high positive predictive value (97\%), its easy applicability and low cost. Therefore, it represents a good screening tool ${ }^{78}$.

A positive examination ( 3 or more desaturation clusters and at least 3 desaturations below 90\%) is considered exhaustive for OSA diagnosis. According to Brouilette criteria, desaturation is defined as a decrease in $\mathrm{SaO} 2 \geq 4 \%$ and the cluster is characterised by at least 5 desaturations that occur in a period of 10-30 min. A useful OSA severity scale is that proposed by the Canadian Brouilette group using the McGill Oximetry Score:

- Category 1, "non-conclusive examination", no desaturation, or desaturation not meeting the subsequent criteria;

- Category 2, mild OSAS: at least 3 "clusters" of desaturation $<90 \%$;

- Category 3, moderate OSAS: at least 3 "clusters" of desaturation $<85 \%$; 
- Category 4, severe OSAS: at least 3 "clusters" of desaturation $<80 \%$.

The diagnostic categories 2,3 and 4 identify, respectively, three increasing classes of priority indication for adenotonsillectomy, and three increasing categories of patients at high risk of developing peri-operative complications ${ }^{48} 49$.

- Watch Peripheral Arterial Tonometry (Watch-PAT). The AAP recommends performing alternative tests in uncomplicated cases of OSA when PSG is not available. Watch-PAT is a portable wrist-worn OSA diagnostic device that incorporates actigraphy to differentiate between wake and sleep stages and a PAT signal probe, which measures the arterial volume change (a signal of sympathetic activation) in a fingertip. Episodes of apnoea and hypopnea induce awakenings and activation of sympathetic nervous system with consequent peripheral vasoconstriction, which results in attenuation of the Watch-PAT signal. WatchPAT records parameters continuously, including PAT (signal and amplitude), pulse rate, oxygen saturation, actigraphy, snoring, and body position. Watch-PAT is equipped with a main body (hardware) and two finger probes: the main body measures sleep time, processes the signal through specific algorithms, provides power and stores data. Remarkable features of PAT are its simplicity, accessibility and ability to measure sleep parameters, including AHI, respiratory disturbance index (RDI), total sleep time (TST) and sleep stages. One major drawback is the absence of a paediatric Watch-PAT probe, and adult devices cannot be always adapted to use in very small children ( $<5$ years). Several authors found that AHI and oxygen desaturation index (ODI) obtained from Watch-PAT can underestimate the degree of sleep apnoea compared to PSG, but for severe OSA (AHI > 10) the diagnostic accuracy is reported to be high. However, specific data on paediatric OSA are very limited. The development of a paediatric probe and algorithm is necessary to increase the validity and clinical application of Watch-PAT for its paediatric use. Future studies will help to clarify whether Watch-PAT could offer an alternative to PSG, which still remains the gold standard technique for diagnosing OSA in children ${ }^{50}$.

\section{Discussion}

The percentage of paediatric patients affected by OSA is often underestimated, and a high proportion of paediatric OSA patients are not receiving correct diagnosis and timely treatment. Lack of treatment of sleep-related breathing disorders places patients at risk of developing growth delay, hyperactivity, attention deficits, learning disabilities and also increases the use of healthcare services and associated costs: it has been reported that the severity of OSA directly correlates with total annual healthcare costs and is age independent ${ }^{51}$. OSA is a condition that needs a clear diagnostic definition in children, and differs from the adult OSA in terms of physiology, clinical manifestation, PSG features and sequelae. It is a worldwide issue to increase clinician awareness on OSA in order to reduce the rate of late diagnosis and avoid OSA-related sequelae. Notwithstanding, the fact that only PSG has been shown to be discriminatory for OSA, any physician can easily suspect OSA clinically. Noisy breathing, mouth breathing, habitual snoring, respiratory pauses, enuresis, morning headache, excessive daytime sleepiness, attention deficit, hyperactivity and learning disorder are the symptoms that should address diagnostic suspicion. Children with suspected OSA should be evaluated by a multidisciplinary team composed of paediatricians, ENT specialists, orthodontists and speech therapists.

PSG is still the gold standard diagnostic tool, but the test is costly and clearly cannot be available in every hospital for assessment of the entire paediatric population that snores. It is likely that less expensive devices can be validated for diagnosis of children OSA in the future ${ }^{11}$. Screening tools, such as nocturnal pulse oximetry combined with clinical indicators, could be useful to select the most PSG deserving children, even if they are specific and not very sensitive. Identifying an ideal screening test, or a series of tests, is still challenging.

According to the American Academy of Otolaryngology-Head and Neck Surgery Foundation (AAO-HNSF) guidelines ${ }^{52}$, PSG should be performed prior to tonsillectomy in children affected by SBD aged 2 to 18 years. The most common indications for PSG assessment prior to tonsillectomy are: Down's syndrome, craniofacial deformities, obesity, neuromuscular diseases, mucopolysaccharidosis, sickle cell disease, symptoms discordant with physical exam and unclear medical history ${ }^{53}$. When OSA is confirmed, further complementary exams can be performed to obtain comprehensive upper airway evaluation: pharyngolaryngoscopy, DISE, lateral cephalograms and maxillofacial computer tomography scans ${ }^{54}$. As for adults, even in children a careful perioperative assessment is recommended prior to any surgical intervention, since asymptomatic OSA may be related to risk of severe perioperative morbidity or mortality, representing a surgical and anesthesiologic issue ${ }^{55}$. The 2014 Guidelines by American Society of Anesthesiologists Task Force on Perioperative Management of patients with OSA apply 
to both adult and paediatric patients; medical history, patient/family interview, screening protocols/questionnaires and clinical examination should always be performed preoperatively. In case of suspected OSA, it may be useful to delay the intervention to obtain more detailed assessment through PSG, whenever possible. Patients affected by OSA should be prepared preoperatively, through CPAP or noninvasive positive pressure ventilation initiation (particularly in case of severe OSA), oral appliances for mandibular advancement and weight loss ${ }^{55}$.

Management of paediatric OSA is still challenging and each task should always be carefully evaluated. Adenotonsillectomy represents the first and main step of the therapeutic program of OSA in children. Nonetheless, it is essential to provide a post-surgical follow-up to identify and evaluate subjects in which, months after adenotonsillectomy, apnoeic events re-emerge, and to investigate and evaluate other possible causes of upper airway obstruction ${ }^{56}{ }^{57}$. Mouth breathing during sleep is very common before surgery, and can persist after surgery causing residual abnormal AHI ${ }^{58-60}$.

Several authors have reported that pharyngeal muscle re-education, using myofunctional re-education, can play a role in reducing mouth-breathing and abnormal breathing during sleep, even after adeno-tonsillectomy ${ }^{6162}$. Rehabilitative techniques, addressed by orthodontists and/or speech therapists, should include restoration of appropriate posture, appropriate tongue resting position with tongue lightly suctioned against palate, appropriate swallowing, appropriate mastication using both back molar areas (i.e., posterior chewing) and appropriate nose breathing. Such behavioural modifications can be obtained through daily re-education exercises ${ }^{63}{ }^{64}$. Retrospective studies show that children who received adequate functional orofacial re-education can achieve long-term OSA remission compared to children treated with adenotonsillectomy and/ or rapid maxillary expansion (RME) without orofacial myofunctional training ${ }^{65}$. Unfortunately, myo-functional exercises are difficult to achieve for children younger than 4 years who do not have sufficient attention and cannot perform them constantly and effectively. Attempts have been described to find passive re-education approaches for these young children ${ }^{63-66}$.

As reported by many authors, upper airway collapsibility after adenotonsillectomy should also represent a therapeutic target. Abnormal collapsibility is related to sleep stages, as different sleep status can modify pharyngeal muscle tone and reflex responses. Additionally, both intrinsic and extrinsic factors have been reported to affect the risk of collapsibility of the upper airways. For instance, fat deposits can induce narrowing of the upper airway and muscle infil- tration can reduce the activity and effectiveness of pharynx dilatation muscles; weight loss in children affected by OSA has been recommended in selected cases ${ }^{267}$.

Continuous positive airway pressure (CPAP) has also been proposed for treatment of paediatric OSA, although its role is controversial especially after adeno-tonsillectomy ${ }^{268-70}$. In adults, CPAP represents the first-choice treatment for patients affected by OSA, according to American College of Physicians ${ }^{71}$. In particular, CPAP is recommended for the treatment of uncomplicated moderate to severe OSA, while it remains optional in mild OSA ${ }^{72}$, since its use has been associated with: (i) reduction of sleep fragmentation, daytime sleepiness and cardiovascular risk, and (ii) improved neurocognitive performances and quality of life ${ }^{73}$. In the paediatric population, CPAP has been reported to be useful in selected cases: (i) patients not eligible for surgery, (ii) patients waiting for interventions, (iii) patients with persisting disease after surgery ${ }^{74}$, and (iv) patients with other diseases, such as Down's syndrome or craniofacial anomalies ${ }^{75}$.

As for adults, in children good compliance to CPAP is crucial to obtain optimal outcomes. Conventionally, the minimum CPAC time is considered to be greater than 4 hours per night, and acceptable CPAP compliance is estimated to be greater than $70 \%$ of nights ${ }^{76}$. In children, the use of CPAP has been associated with improvement in attention, somnolence, school performance and global quality of life perception ${ }^{75}$. Nonetheless, the reported compliance rate to CPAP in children is not very high, due to the short length of CPAP use per night and the high drop-out rate; probably, the limited use of CPAP in the paediatric population can also be related to comorbidities or syndromes associated with developmental delays ${ }^{75}$. As in the adult population, the management of paediatric CPAP is still a multidisciplinary issue, and it has been reported that the presence of respiratory therapists may improve the CPAP compliance ${ }^{75}$.

\section{Conclusions}

Any child with suspected OSA should be submitted for integrated clinical and instrumental evaluation. In particular:

- children with suspected OSA should also be managed by a multidisciplinary team composed of a paediatrician, ENT specialist, orthodontist and speech therapist ${ }^{77-79}$;

- initial instrumental evaluation can be performed by nocturnal pulse oximetry;

- PSG is still the gold standard for OSA diagnosis in children;

- data on paediatric OSA should always be evaluated carefully. 


\section{Conflict of interest statement}

None declared.

\section{References}

1 Marcus CL, Greene MG, Carroll JL. Blood pressure in children with obstructive sleep apnea. Am J Respir Crit Care Med 1998;157:1098103. https://doi.org/10.1164/ajrccm.157.4.9704080.

2 Guilleminault C, Lee JH, Chan A. Pediatric obstructive sleep apnea syndrome. Arch Pediatr Adolesc Med 2005;159:775-85. https://doi. org/10.1001/archpedi.159.8.775.

3 Beebe DW, Ris MD, Kramer ME, et al. The association between sleep disordered breathing, academic grades, and cognitive and behavioral functioning among overweight subjects during middle to late childhood. Sleep 2010;33:1447-56. https://doi.org/10.1093/sleep/33.11.1447.

4 Richards W, Ferdman RM. Prolonged morbidity due to delays in the diagnosis and treatment of obstructive sleep apnea in children. Clin Pediatr (Phila) 2000;39:103-8. https://doi. org/10.1177/000992280003900205.

5 Marcus CL, Omlin KJ, Basinki DJ, et al. Normal polysomnographic values for children and adolescents. Am Rev Respir Dis 1992;146:1235-9. https://doi.org/10.1164/ajrccm/146.5_Pt_1.1235.

6 Marcus CL. Sleep-disordered breathing in children. Am J Respir Crit Care Med 2001;164:16-30. https://doi.org/10.1164/ ajrccm.164.1.2008171.

7 Guilleminoult C, Pelayo R, Leger D, et al. Recognition of sleep disordered breathing in children. Pediatrics 1996;98:871-82.

8 American Thoracic Society. Standards and indications for cardiopulmonary sleep studies in children. Am J Respir Crit Care Med 1996;153:866. https://doi.org/10.1164/ajrccm.153.2.8564147.

9 American Academy of Sleep Medicine. International Classification of Sleep Disorders. $3^{\text {rd }}$ ed. American Academy of Sleep Medicine, Darien 2014.

10 Aurora RN, Zak RS, Karippot A, et al. American Academy of Sleep Medicine. Practice parameters for the respiratory indications for polysomnography in children. Sleep 2011;34:379-88. https://doi. org/10.1093/sleep/34.3.379.

11 Marcus CL, Brooks LJ, Draper KA, et al. Diagnosis and management of childhood obstructive sleep apnea syndrome. Pediatrics 2012;130:576-84. https://doi.org/10.1542/peds.2012-1672.

12 Brunetti L, Rana S, Lospalluti ML et al. Prevalence of obstructive sleep-apnea sindrome in a cohort of 1207 children of southern Italy. Chest 2001;120:1930-5. https://doi.org/10.1378/chest.120.6.1930.

13 Fregosi RF, Quan SF, Kaemingk KL, et al. Sleep disordered breathing, pharyngeal size and soft tissue anatomy in children. J Appl Physiol 1985;2003;95:2030-8. https://doi.org/10.1152/ japplphysiol.00293.2003.

14 Marcus CL, McColley SA, Carroll JL, et al. Upper airway collapsibility in children with obstructive sleep apnea syndrome. J Appl Physiol 1994;77:918-24. https://doi.org/10.1152/ jappl.1994.77.2.918.

15 Marcus CL, Moore RH, Rosen CL, et al.; Childhood Adenotonsillectomy Trial (CHAT). A randomized trial of adenotonsillectomy for childhood sleep apnea. N Engl J Med 2013;368:2366-76. https:// doi.org/10.1056/NEJMoa1215881.

16 Spilsbury JC, Storfer-Isser A, Rosen CL, et al. Remission and incidence of obstructive sleep apnea from middle childhood to late adolescence. Sleep 2015;38:23-9. https://doi.org/10.5665/sleep.4318.

17 Hannon TS, Rofey DL, Ryan CM, et al. Relationships among obstructive sleep apnea, anthropometric measures, and neurocog- nitive functioning in adolescents with severe obesity. J Pediatr 2012;160:732-5. https://doi.org/10.1016/j.jpeds.2011.10.029.

18 Lam YY, Chan EY, Ng DK, et al. The correlation among obesity, apnea-hypopnea index, and tonsil size in children. Chest 2006;130:1751-6. https://doi.org/10.1378/chest.130.6.1751.

19 Baugh RF, Archer SM, Mitchell RB, et al.; American Academy of Otolaryngology-Head and Neck Surgery Foundation. Clinical practice guideline: tonsillectomy in children. Otolaryngol Head Neck Surg 2011;144(1 Suppl):S1-30. https://doi. org/10.1177/0194599810389949.

20 Costa DJ, Mitchell R. Adenotonsillectomy for obstructive sleep apnea in obese children: a meta- analysis. Otolaryngol Head Neck Surg 2009;140:455-60. https://doi.org/10.1016/j.otohns.2008.12.038.

21 Bhattacharjee R, Kim J, Kheirandish-Gozal L, et al. Obesity and obstructive sleep apnea syndrome in children: a tale of inflammatory cascades. Pediatr Pulmonol 2011;46:313-23. https://doi. org/10.1002/ppul.21370.

22 Kheirandish-Gozal L, Sans Capdevila O, Kheirandish E, et al. Elevated serum aminotransferase levels in children at risk for obstructive sleep apnea. Chest 2008;133:92-9. https://doi.org/10.1378/ chest.07-0773.

23 Redline S, Storfer-Isser A, Rosen CL, et al. Association between metabolic syndrome and sleep-disordered breathing in adolescents. Am J Respir Crit Care Med 2007;176:401-8. https://doi. org/10.1164/rccm.200703-375OC.

24 Redline S, Tishler PV, Schluchter M, et al. Risk factors for sleep- disordered breathing in children. Associations with obesity, race, and respiratory problems. Am J Respir Crit Care Med 1999;159:152732. https://doi.org/10.1164/ajrccm.159.5.9809079

25 Goldbart AD, Greenberg-Dotan S, Tal A. Montelukast for children with obstructive sleep apnea: a double-blind, placebo-controlled study. Pediatrics 2012;130:e575-80. https://doi.org/10.1542/ peds.2012-0310.

26 Villa MP, Malagola C, Pagani J, et al. Rapid maxillary expansion in children with obstructive sleep apnea syndrome: 12-month follow-up. Sleep Med 2007;8:128-34. https://doi.org/10.1016/j. sleep.2006.06.009.

27 Zettergren-Wijk L, Forsberg CM, Linder-Aronson S. Changes in dentofacial morphology after adeno-tonsillectomy in young children with obstructive sleep apnoea - a 5-year follow-up study. Eur $\mathbf{J}$ Orthod 2006;28:319-26. https://doi.org/10.1093/ejo/cji119.

28 Alves RS, Resende MB, Skomro RP, et al. Sleep and neuromuscular disorders in children. Sleep Med Rev 2009;13:133-48. https://doi. org/10.1016/j.smrv.2008.02.002.

29 Marcus CL, Keens TG, Bautista DB, et al. Obstructive sleep apnea in children with Down syndrome. Pediatrics 1991;88:132-9.

30 Bull MJ; Committee on Genetics. Health supervision for children with Down syndrome. Pediatrics 2011;128:393-406. https://doi. org/10.1542/peds.2011-1605.

31 Tapia IE, Shults J, Doyle LW, et al. Caffeine for apnea of prematurity - Sleep Study Group. Perinatal risk factors associated with the obstructive sleep apnea syndrome in school-aged children born preterm. Sleep 2016;39:737-42. https://doi.org/10.5665/sleep.5618.

32 Weinstock TG, Rosen CL, Marcus CL, et al. Predictors of obstructive sleep apnea severity in adenotonsillectomy candidates. Sleep 2014;37:261-9. https://doi.org/10.5665/sleep.3394.

33 Brietzke SE, Katz ES, Roberson DW. Can history and physical examination reliably diagnose pediatric obstructive sleep apneal hypopnea syndrome? A systematic review of the literature. Otolaryngol Head Neck Surg 2004;131:827-32. https://doi.org/10.1016/j. otohns.2004.07.002.

34 Chervin RD, Hedger K, Dillon JE, et al. Pediatric sleep question- 
naire (PSQ): validity and reliability of scales for sleep-disordered breathing, snoring, sleepiness, and behavioral problems. Sleep Med 2000;1:21-32.

35 Brouilette R, Hanson D, David R, et al. A diagnostic approach to suspected obstructive sleep apnea in children. J Pediatr 1984;105:10-4. https://doi.org/10.1016/s0022-3476(84)80348-0.

36 Carroll JL, McColley SA, Marcus CL, et al. Inability of clinical history to distinguish primary snoring from obstructive sleep apnea syndrome in children. Chest 1995;108:610-8. https://doi. org/10.1378/chest.108.3.610.

37 Kadmon G, Chung SA, Shapiro CM. I'M SLEEPY: a short pediatric sleep apnea questionnaire. Int $\mathrm{J}$ Pediatr Otorhinolaryngol 2014;78:2116-20. https://doi.org/10.1016/j.ijporl.2014.09.018.

38 Melendres MC, Lutz JM, Rubin ED, et al. Daytime sleepiness and hyperactivity in children with suspected sleep-disordered breathing. Pediatrics 2004;11:768-75. https://doi.org/10.1542/peds.2004-0730.

39 Friedman M, Ibrahim H, Joseph NJ. Staging of obstructive sleep apnea/hypopnea syndrome: a guide to appropriate treatment. Laryngoscope 2004;114:454-9. https://doi.org/10.1097/00005537200403000-00013.

40 Durr ML, Meyer AK, Kezirian EJ, et al. Drug-induced sleep endoscopy in persistent pediatric sleep-disordered breathing after adenotonsillectomy. Arch Otolaryngol Head Neck Surg 2012;138:63843. https://doi.org/10.1001/archoto.2012.1067.

41 Wootten CT, Chinnadurai S, Goudy SL. Beyond adenotonsillectomy: outcomes of sleep endoscopy-directed treatments in pediatric obstructive sleep apnea. Int J Pediatr Otorhinolaryngol 2014;78:115862. https://doi.org/10.1016/j.ijporl.2014.04.041.

42 Chan DK, Liming BJ, Horn DL, et al. A new scoring system for upper airway pediatric sleep endoscopy. JAMA Otolaryngol Head Neck Surg 2014;140:595-602. https://doi.org/10.1001/jamaoto.2014.612.

43 Lam DJ, Weaver EM, Macarthur CJ, et al. Assessment of pediatric obstructive sleep apnea using a drug-induced sleep endoscopy rating scale. Laryngoscope 2016;126:1492-8. https://doi.org/10.1002/lary.25842.

44 Ulualp SO, Szmuk P. Drug-induced sleep endoscopy for upper airway evaluation in children with obstructive sleep apnea. Laryngoscope 2013;123:292-7. https://doi.org/10.1002/lary.23832.

45 Friedman NR, Parikh SR, Ishman SL, et al. The current state of pediatric drug-induced sleep endoscopy. Laryngoscope 2017;127:26672. https://doi.org/10.1002/lary.26091.

46 Zaremba EK, Barkey ME, Mesa C, et al. Making polysomnography more "child friendly:" a family-centered care approach. J Clin Sleep Med 2005;1:189-98.

47 Berry RB, Brooks R, Gamaldo CE, et al. The AASM Manual for the Scoring of Sleep and Associated Events: Rules, Terminology and Technical Specifications, Version 2.4, www.aasmnet.org, American Academy of Sleep Medicine, Darien, IL 2017.

48 Wilson K, Lakheeram I, Morielli A, et al. Can assessment for obstructive sleep apnea help predict postadenotonsillectomy respiratory complications? Anesthesiology 2002;96:313-22. https://doi. org/10.1097/00000542-200202000-00015.

49 Ayas NT, Pittman S, MacDonald M, et al. Assessment of a wristworn device in the detection of obstructive sleep apnea. Sleep Med 2003;4:435-42.

50 Serra A, Cocuzza S, Maiolino L, et al. The watch-pat in pediatrics sleep disordered breathing: pilot study on children with negative nocturnal pulse oximetry. Int J Pediatr Otorhinolaryngol 2017;97:245-50. https://doi.org/10.1016/j.ijporl.2017.04.021.

51 Toraldo DM, Passali D, Sanna A, et al. Cost-effectiveness strategies in OSAS management: a short review. Acta Otorhinolaryngol Ital 2017;37:447-53. https://doi.org/10.14639/0392-100X-1520.

52 Roland PS, Rosenfeld RM, Brooks LJ, et al. Clinical practice guideline: polysomnography for sleep-disordered breathing prior to tonsillectomy in children. Otolaryngol Head Neck Surg 2011;145(1 Suppl):S1-15 https://doi.org/10.1177/0194599811409837.

53 Setabutr D, Adil EA, Chaikhoutdinov I, et al. Impact of the pediatric tonsillectomy and polysomnography clinical practice guidelines. Int J Pediatr Otorhinolaryngol 2014;78:517-21.

54 Garg RK, Afifi AM, Garland CB, et al. Pediatric Obstructive Sleep Apnea: Consensus, Controversy, and Craniofacial Considerations. Plast Reconstr Surg 2017;140:987-97. https://doi.org/10.1097/ PRS.0000000000003752.

55 American Society of Anesthesiologists Task Force on Perioperative Management of Patients with Obstructive Sleep Apnea. Practice Guidelines for the Perioperative Management of Patients with $\mathrm{Ob}$ structive Sleep Apnea: An Updated Report by the American Society of Anesthesiologists Task Force on Perioperative Management of Patients with Obstructive Sleep Apnea. Anesthesiology 2014;120:26886. https://doi.org/10.1097/ALN.0000000000000053.

56 Guilleminault C, Huang YS, Glamann C, et al. Adenotonsillectomy and obstructive sleep apnea in children: a prospective survey. Otolaryngol.Head-Neck Surg 2007;136:169-75. https://doi. org/10.1016/j.otohns.2006.09.021.

57 Huang YS, Guilleminault C, Lee LA, et al. Treatment outcomes of adenotonsillectomy for children with obstructive sleep apnea: a prospective longitudinal study. Sleep 2014;37:71-6. https://doi. org/10.5665/sleep.3310.

58 Bhattacharjee R, Kheirandish-Gozal L, Spruyt K, et al. Adenotonsillectomy outcomes in treatment of obstructive sleep apnea in children: a multicenter retrospective study. Am J Respir Crit Care Med 2010;182:676-83. https://doi.org/10.1164/rccm.200912-1930OC.

59 Sullivan S, Li K, Guilleminault C. Nasal obstruction in children with Sleep Disordered Breathing. Ann Acad Med Singapore 2008;37:645-8.

60 Lee SH, Choi JH, Shin C, et al. How does open-mouth breathing influence upper airway anatomy? Laryngoscope 2007;117:1102-6. https://doi.org/10.1097/MLG.0b013e318042aef7.

${ }_{61}$ Guimarães KC, Drager LF, Genta PR, et al. Effects of oropharyngeal exercises on patients with moderate obstructive sleep apnea syndrome. Am J Respir Crit Care Med 2009;179:962-6. https://doi. org/10.1164/rccm.200806-9810C.

62 Camacho C, Certal V, Abdullatif J, et al. Myofunctional therapy to treat obstructive sleep apnea: a systematic review and meta-analysis. Sleep 2015;38:669-75. https://doi.org/10.5665/sleep.4652.

63 Moeller J, Paskay LC, Gelb ML. Myofunctional therapy: a novel treatment of pediatric sleep-disordered breathing. Sleep Med Clin 2014;9:235-39.

64 Villa MP, Brasili L, Ferretti, et al. Oropharyngeal exercises to reduce symptoms of OSA after AT. Sleep Breath 2015;19:281-9. https://doi. org/10.1007/s11325-014-1011-z.

65 Guilleminault C, Huang YS, Monteyrol PJ, et al. Critical role of myofascial reeducation in sleep-disordered breathing. Sleep Med 2013;14:518-25. https://doi.org/10.1016/j.sleep.2013.01.013.

${ }_{66}$ Malagutti N, Di Laora A, Barbetta C, et al. Is peripheral oxygen saturation a reliable predictor of upper airways air-flow limitation? J Emerg Med 2018;55:627-34. https://doi.org/10.1016/j. jemermed.2018.07.007.

67 Chuang LC, Lian YC, Hervy-Auboiron M, et al. Passive myofunctional therapy applied on children with obstructive sleep apnea: a 6-month follow-up. J Formosan Medical Association 2017;116:53641. https://doi.org/10.1016/j.jfma.2016.08.002.

68 Schlenker WL, Jennings BD, Jeiroudi MT, et al. The effects of chronic absence of active nasal respiration on the growth of the skull: a pilot study. Am J Orthod Dentofacial Orthop 2000;117:706-13. 
69 Cheng MC, Enlow DH, Papsidero M, et al. Developmental effects of impaired breathing in the face of the growing child. Angle Orthod 1988;58:309-20.

70 Chauvois A, Fournier M, Girardin F. Rééducation des fonctions dans la thérapeutique orthodontiques. Paris: S.I.D; 1991.

71 Qaseem A, Holty JE, Owens DK, et al. Management of obstructive sleep apnea in adults: A clinical practice guideline from the American College of Physicians. Ann Intern Med 2013;159:471-83. https://doi.org/10.7326/0003-4819-159-7-201310010-00704.

72 Kushida CA, Littner MR, Hirshkowitz M, et al. Practice parameters for the use of continuous and bilevel positive airway pressure devices to treat adult patients with sleep-related breathing disorders. Sleep 2006;29:375-80. https://doi.org/10.1093/sleep/29.3.375.

73 Gay P, Weaver T, Loube D, et al. Evaluation of positive airway pressure treatment for sleep related breathing disorders in adults. Sleep 2006;29:381-401. https://doi.org/10.1093/sleep/29.3.381.

74 Sharma SD, Kanona H, Kumar G, et al. Latest trends in the assessment and management of paediatric snoring and sleep apnoea. J Laryngol Otol 2016;130:482-9. https://doi.org/10.1017/ S0022215116000980.
75 Riley EB, Fieldston ES, Xanthopoulos MS, et al. Financial analysis of an intensive pediatric continuous positive airway pressure program. Sleep 2017;40. https://doi.org/10.1093/sleep/zsw051.

76 Schwab RJ, Badr SM, Epstein LJ, et al. An official American Thoracic Society statement: continuous positive airway pressure adherence tracking systems. The optimal monitoring strategies and outcome measures in adults. Am J Respir Crit Care Med 2013;188:61320. https://doi.org/10.1164/rccm.201307-1282ST.

77 Montevecchi F, Bellini C, Meccariello G, et al. Transoral roboticassisted tongue base resection in pediatric obstructive sleep apnea syndrome: case presentation, clinical and technical consideration. Eur Arch Otorhinolaryngol 2017;274:1161-6. https://doi. org/10.1007/s00405-016-4269-x.

78 Villa MP, Bellussi LM, De Benedetto M, et al. The "Italian way" to counteract obstructive sleep apnoea syndrome in children. Acta Otorhinolaryngol Ital 2018;38:393-4. https://doi. org/10.14639/0392-100X-2157.

79 Cassano M, Russo G, Granieri C, et al. Modification of growth, immunologic and feeding parameters in children with OSAS after adenotonsillectomy. Acta Otorhinolaryngol Ital 2018;38:124-30. https://doi.org/10.14639/0392-100X-1380.

Received: April 26, 2019 - Accepted: August 11, 2019

How to cite this article: Savini S, Ciorba A, Bianchini C, et al. Assessment of obstructive sleep apnoea (OSA) in children: an update. Acta Otorhinolaryngol Ital 2019;39:289-297. https://doi.org/10.14639/0392-100X-N0262

Address for correspondence: Andrea Ciorba, ENT \& Audiology Department, University Hospital of Ferrara, via Aldo Moro 8, 44124 Ferrara, Italy. Tel. +390532 239745. E-mail: andrea.ciorba@unife.it 